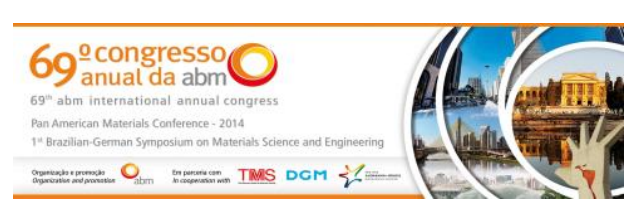

Tema: Materiais cerâmicos, compósitos e poliméricos

\title{
ESTUDO DA VIABILIDADE TÉCNICA DE INCORPORAÇÃO DE LAMA DE ALTO FORNO EM MASSA ARGILOSA*
}

\author{
Alessandra Savazzini dos Reis ${ }^{1}$ \\ Viviana Possamai Della Sagrillo² \\ Francisco Rolando Valenzuela Diaz ${ }^{3}$
}

\section{Resumo}

A incorporação de resíduo na massa argilosa é uma alternativa para diminuir o consumo de matéria-prima dando simultaneamente um destino adequado ao resíduo e assim preservar o meio ambiente. Este trabalho visa estudar a viabilidade técnica de utilização da lama de alto forno em massa argilosa usada na indústria de cerâmica vermelha. Neste sentido foram obtidas amostras da lama de alto forno e de argila e submetidas a ensaios de caracterização química, mineralógica e microestrutural. Amostras com teores de lama de alto forno variando entre $5 \%$ e $90 \%$ foram produzidas e queimadas em forno industrial à temperatura entre $800^{\circ} \mathrm{C}$ e $900^{\circ} \mathrm{C}$ durante 24 horas. As características tecnológicas avaliadas foram: absorção de água, porosidade aparente, massa específica aparente, perda de massa e resistência mecânica. Os estudos mostram que a lama de alto forno contribui para economia energética permitindo eficácia de queima. Os corpos-de-prova com até $5 \%$ de lama de alto forno obtiveram os melhores resultados nas características analisadas.

Palavras-chave: Resíduo; Lama de alto forno; Cerâmica vermelha; Economia energética.

\section{TECHNICAL FEASIBILITY STUDY OF INCORPORATION OF BLAST FURNACE SLUDGE IN CLAYEY MASS}

\section{Abstract}

The incorporation of residue in the clayey mass is an alternative to reduce material consumption of raw materials to making a suitable destination for residue and preserve the environment. The aim of this paper is to study the technical feasibility of incorporating the blast furnace sludge in clayey mass used in the structural ceramic industry. Samples of blast furnace sludge and clay were obtained and tested for chemical, mineralogical and microstructural characterization. Samples containing blast furnace sludge between $5 \%$ and $90 \%$ were fired in the industrial furnace at a temperature $800^{\circ} \mathrm{C}$ and $900^{\circ} \mathrm{C}$ for 24 hours. The following were evaluated: water absorption, apparent porosity, bulk density, weight loss and mechanical strength. Studies show that the blast furnace sludge contributes to energy saving and provides firing efficacy. The best results in the characteristics analyzed were obtained in the samples with $5 \%$ of blast furnace sludge.

Keywords: Residue; Blast furnace sludge; Structural ceramic; Energy saving.

1 Engenheira Civil, Mestre, professora, Coordenadoria de Edificações, IFES, Colatina, ES, Brasil.

2 Química Industrial, Doutora, professora, Coordenadoria de Metalurgia, IFES, Vitória, ES, Brasil.

3 Engenheiro Químico, Doutor, professor, PMT, USP, São Paulo, SP, Brasil.

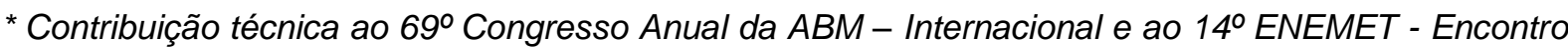
Nacional de Estudantes de Engenharia Metalúrgica, de Materiais e de Minas, 21 a 25 de julho de 2014, São Paulo, SP, Brasil.
} 


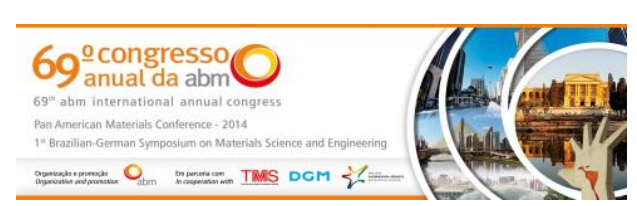

\section{INTRODUÇÃO}

\subsection{Lama de Alto forno (LAF)}

O aço é um produto reciclável e de extrema importância na atividade humana, figura como elemento essencial em diversas cadeias produtivas. O Brasil, em 2011, se destacou como terceiro produtor mundial de minério de ferro, principal matéria-prima do aço [1].

O parque produtor de aço no Brasil, que ocupa o 9o lugar como produtor mundial, está instalado em dez estados, sendo que $94 \%$ da produção de aço no país está concentrada na região Sudeste (Figura 1). O setor possui uma capacidade instalada para fabricar mais de 47milhões de toneladas de aço por ano, e conta com 29 usinas de grande porte. As siderúrgicas são responsáveis por terem gerado 109mil empregos em 2011, e respondem por 4\% no PIB brasileiro [2]. Verifica-se com os dados obtidos a importância do setor para economia brasileira.

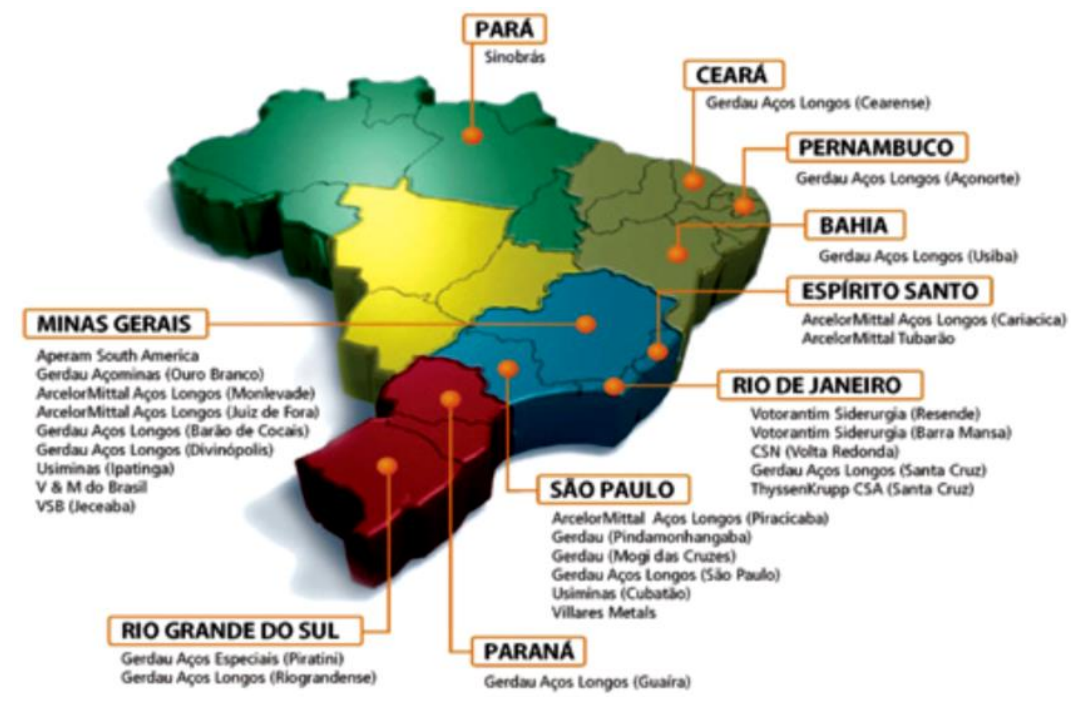

Figura 1. Parque produtor de aço no Brasil [2]

O processo de fabricação do aço gera vários resíduos ao longo das etapas. Estimase que no Brasil, em 2011, foram gerados $630 \mathrm{~kg}$ de resíduo na produção de uma tonelada de aço bruto [2]. Um dos resíduos é a lama de alto forno, que é gerada após a etapa de limpeza a úmido dos gases de alto forno e da separação dos particulados sólidos. A lama de alto forno é um resíduo de granulometria fina e é constituído predominantemente por óxidos de ferro, provenientes do minério de ferro e de finos de coque, provenientes do carbono $[3,4]$.

O carvão usado na siderúrgica, fonte do carbono, atua como combustível e permite alcançar altas temperaturas (cerca de $1500^{\circ} \mathrm{C}$ ) necessárias à fusão do minério de ferro, além de atuar como agente redutor associando-se ao oxigênio que se desprende do minério deixando livre o Ferro.

Os resíduos da siderurgia podem constituir uma fonte de contaminação de solo, ar e água se não forem dispostos adequadamente, o que ocorre em algumas indústrias. E ainda segundo Almeida e Melo [5], a lama de alto forno é um resíduo de classe I, ou seja, perigoso por apresentar fenóis acima do limite especificado pela norma ABNT NBR10004/2004. Isso faz com que o aproveitamento dos resíduos no processo de produção do aço nem sempre seja viável tecnicamente e ambientalmente. A incorporação da lama de alto forno na massa cerâmica torna-se

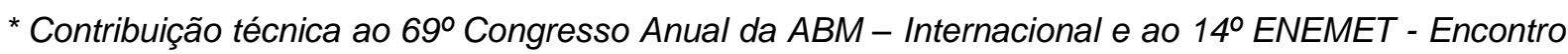
Nacional de Estudantes de Engenharia Metalúrgica, de Materiais e de Minas, 21 a 25 de julho de 2014, São Paulo, SP, Brasil. 


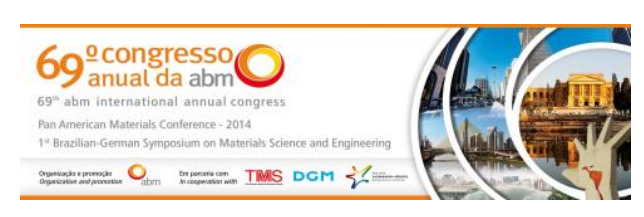

uma alternativa de uso para o resíduo e de diminuição do consumo de matéria prima, a argila, e assim de preservação do meio ambiente.

\subsection{Massa Argilosa}

A indústria de "cerâmica vermelha", que fabrica produtos cerâmicos estruturais, tais como, telhas e tijolos furados, ocupa um papel importante e de destaque na construção civil brasileira e utiliza como matéria-prima, a argila. A massa argilosa é moldada na forma final de uso e queimada a temperaturas elevadas [6].

A argila usada na fabricação de cerâmica vermelha é de natureza heterogênea, constituída de materiais plásticos e não plásticos, com grande número de composições, o que permite inserir resíduos provenientes de diferentes processos industriais.

A incorporação de resíduos à massa argilosa deve ser precedida de caracterização química, mineralógica e microestrutural dos materiais e da análise das propriedades cerâmicas das massas com resíduos para verificação da viabilidade técnica.

As matérias primas a serem usadas nas massas cerâmicas podem ser avaliadas através de algumas características cerâmicas, tais como: tensão de ruptura à flexão com valor mínimo de $60 \mathrm{Kgf} / \mathrm{cm}^{2}(6 \mathrm{MPa})$; absorção de água com valor máximo de 25\%; porosidade aparente com valor máximo de 35\%; e massa específica aparente com valores no intervalo aproximado de $1,5 \mathrm{~g} / \mathrm{cm}^{3}$ a $2,0 \mathrm{~g} / \mathrm{cm}^{3}[6]$.

\subsection{Incorporação da Lama de Alto forno em Massa Argilosa}

A incorporação de lama de alto forno em cerâmica vermelha, segundo Mothé [7], chegou ao teor máximo de uso de $5 \%$ (em massa) na mistura argilosa para evitar 0 efeito deletério causado pela porosidade gerada pela combustão dos finos de coque, da decomposição da calcita e pela presença de compostos de Ferro na microestrutura da cerâmica.

A lama foi adicionada em teores de $5 \%$ a $20 \%$ (em massa), em cerâmica vermelha e os corpos de prova com até $10 \%$ de lama obtiveram resultados satisfatórios, porém a partir daí a lama contribuiu para aumento da absorção de água, redução da tensão de ruptura à flexão e aumento da retração linear de queima [8].

A lama de alto forno serve como combustível e fonte metálica devido aos altos teores de carbono e ferro nela contidos contribuindo assim para economia energética nas fábricas de cerâmica vermelha $[4,9,10]$.

Verifica-se com os dados obtidos que há poucos estudos científicos sobre a incorporação da lama de alto forno, que pode agir como fonte de energia durante a queima da massa argilosa contribuindo para a economia financeira nas fábricas.

Nesse sentido, este trabalho visa estudar a viabilidade técnica de incorporação da lama de alto forno em massa argilosa usada na indústria de cerâmica vermelha.

\section{MATERIAIS E MÉTODOS}

As amostras de argila e da lama de alto forno (LAF) estudadas foram coletadas em pilhas de armazenagem de matéria-prima em fábrica de cerâmica vermelha situada no estado do Espírito Santo, Figura 2 (a) e (b). Depois de coletadas, as amostras foram destorroadas com auxílio de almofariz. Foi feita homogeneização e quarteamento e as amostras dos materiais foram divididas em três partes para peneiramento nas peneiras \#40, \#80, \#200 da ABNT com abertura de malha de

\footnotetext{
* Contribuição técnica ao $69^{\circ}$ Congresso Anual da ABM - Internacional e ao 14ํㅡㄹ ENEMET - Encontro Nacional de Estudantes de Engenharia Metalúrgica, de Materiais e de Minas, 21 a 25 de julho de 2014, São Paulo, SP, Brasil.
} 


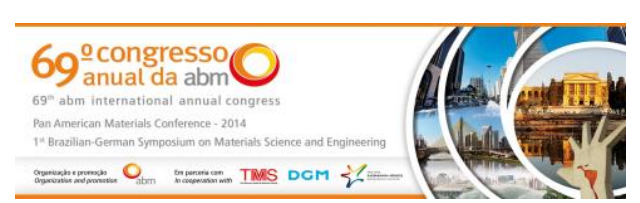

$0,42 \mathrm{~mm} ; 0,18 \mathrm{~mm}$ e $0,074 \mathrm{~mm}$, respectivamente, de acordo com a metodologia dos ensaios a serem realizados. A Figura 2 (c) mostra o aspecto da argila e da lama de alto forno peneiradas na peneira \#80 da ABNT.

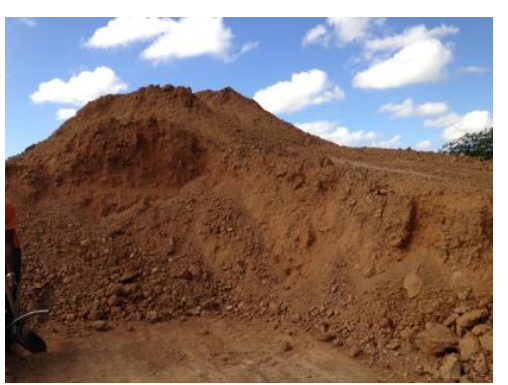

(a) Estocagem de argila

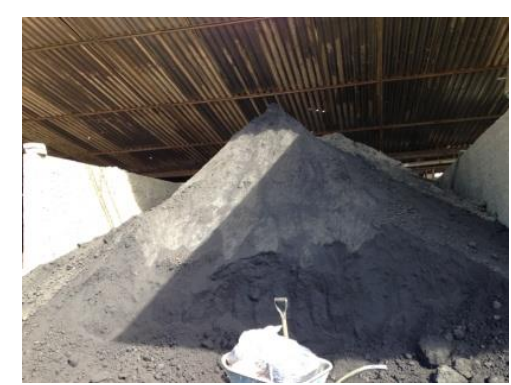

(b) Lama de alto forno

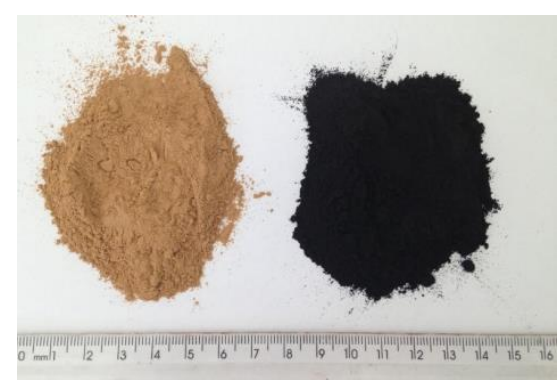

(c) Materiais peneirados \#80

Figura 2. Materiais nas pilhas de armazenagem e após peneiramento

A argila e a lama de alto forno in natura foram caracterizadas por fluorescência de raios X (FRX) em espectrômetro marca Philips modelo PW2400, difração de raios X (DRX) com fonte de cobre (radiação $K \alpha$ ) em aparelho Philips X-PERT MPD, microscopia eletrônica de varredura (MEV) em microscópio eletrônico de varredura marca Philips XL-30, limites de Atterberg, conforme normas ABNT [11,12] e teor de umidade [13].

Após caracterização foram confeccionados corpos de prova da mistura argilosa e resíduo, com massa seca de $10 \mathrm{~g}$. Os corpos de prova esféricos (esferas) foram moldados manualmente com quantidade de água suficiente para perfeita moldagem obedecendo ao diâmetro médio de $20 \mathrm{~mm}$. Os corpos de prova prismáticos (barras), com dimensões de $20 \mathrm{~mm} \times 60 \mathrm{~mm} \times 5 \mathrm{~mm}$ foram confeccionados por prensagem a $250 \mathrm{Kgf} / \mathrm{cm}^{2}$ em prensa Marcon com capacidade de carga de $15 \mathrm{t}$. A Figura 3 apresenta as barras confeccionadas com a argila (Figura 3a) e com a LAF (Figura 3b) em três estágios, recém-conformada, seca em estufa a $105 \pm 5^{\circ} \mathrm{C}$ e após queima, além de esferas de LAF secas em estufa a $105 \pm 5^{\circ} \mathrm{C}$ (Figura $3 \mathrm{c}$ ) e esferas de argila após queima (figura $3 d$ ).

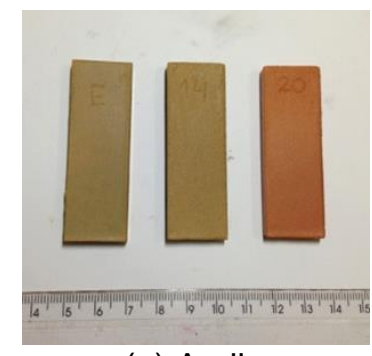

(a) Argila

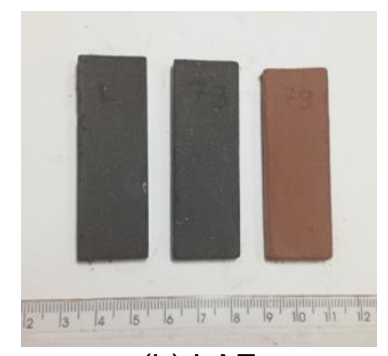

(b) LAF

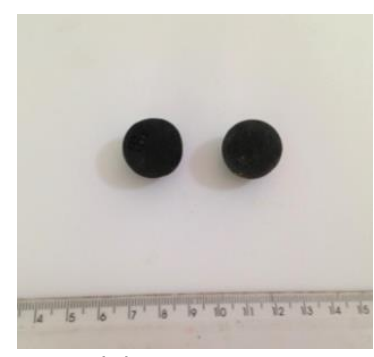

(c) LAF seca

Figura 3. Barras e esferas conformadas

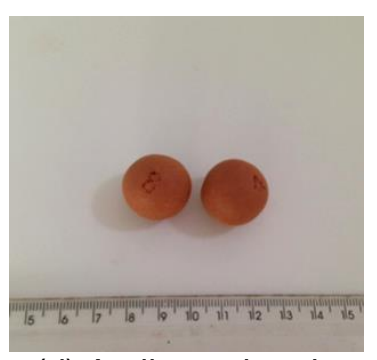

(d) Argila queimada

A dosagem dos corpos de prova foi feita com os teores de lama de alto forno de $5 \%$, $10 \%, 20 \%, 30 \%, 40 \%, 50 \%, 60 \%, 70 \%, 80 \%$ e $90 \%$ (em massa). Além de corpos de prova de argila sem incorporação da lama de alto forno.

Os corpos de prova foram secos em estufa por 24horas à temperatura de $105 \pm 5^{\circ} \mathrm{C}$. Uma parte dos corpos de prova foi reservada para realização do ensaio de resistência mecânica. A seguir parte dos corpos de prova foi queimada em forno industrial tipo túnel em fábrica de cerâmica vermelha com tempo de queima de 24 horas à temperatura entre $800^{\circ} \mathrm{C}$ e $900^{\circ} \mathrm{C}$. As características tecnológicas avaliadas após a queima foram: absorção de água, porosidade aparente, massa específica

\footnotetext{
* Contribuição técnica ao $69^{\circ}$ Congresso Anual da ABM - Internacional e ao 14ํㅡㄹ ENEMET - Encontro Nacional de Estudantes de Engenharia Metalúrgica, de Materiais e de Minas, 21 a 25 de julho de 2014, São Paulo, SP, Brasil.
} 
aparente, perda de massa, resistência à compressão axial (esferas), resistência à flexão (barras), perda de massa e retração de queima de acordo com metodologia proposta por Santos [6].

\section{RESULTADOS E DISCUSSÃO}

\subsection{Caracterização dos Materiais}

O resultado da análise química (Tabela 1) é apresentado em termos do percentual em peso dos óxidos constituintes e perda ao fogo. Analisando os dados da tabela podemos verificar que a argila apresenta uma composição química típica de matériaprima argilosa, ou seja, rica em sílica e alumina, com teores de 43,62\% e 28,15\% respectivamente. Esses teores de $\mathrm{SiO}_{2}, \mathrm{Al}_{2} \mathrm{O}_{3}$ e da perda ao fogo situam-se nos intervalos referenciados em Santos [6], sendo $\mathrm{SiO}_{2}$ entre $43,2 \%$ e $77,6 \%$ e o $\mathrm{Al}_{2} \mathrm{O}_{3}$ entre $6,8 \%$ e $38 \%$. Quanto a perda ao fogo, o intervalo é $6 \%$ a $15,7 \%$ para matériasprimas argilosas de cerâmica vermelha.

O percentual de $12,04 \%$ de óxido de ferro é o responsável pela coloração avermelhada após queima. A concentração dos óxidos de sódio ( $\mathrm{Na}_{2} \mathrm{O}$ ) e de potássio $\left(\mathrm{K}_{2} \mathrm{O}\right)$ não é significativa, portanto mesmo sendo considerados óxidos fundentes contribuem pouco na formação da fase líquida.

A lama de alto forno apresenta predominância de óxidos de ferro $(61,16 \%)$ e perda ao fogo alta em relação à argila, o valor alto está associado à combustão dos finos de coque presentes na lama [4]. O teor de $\mathrm{SiO}_{2}$ de $5,11 \%$ está associado às partículas de quartzo.

Tabela 1. Composição química

\begin{tabular}{c|c|c}
\hline \multicolumn{3}{c}{ Composição elementar expressa em óxidos (\%) } \\
\hline Elementos & Argila & $\mathrm{LAF}$ \\
\hline $\mathrm{SiO}_{2}$ & 43,62 & 5,11 \\
\hline $\mathrm{Al}_{2} \mathrm{O}_{3}$ & 28,15 & 1,80 \\
\hline $\mathrm{Fe}_{2} \mathrm{O}_{3}$ & 12,04 & 61,16 \\
\hline $\mathrm{TiO}_{2}$ & 1,34 & 0,09 \\
\hline $\mathrm{K}_{2} \mathrm{O}$ & 1,02 & 0,23 \\
\hline $\mathrm{MgO}$ & 0,38 & 0,70 \\
\hline $\mathrm{P}_{2} \mathrm{O}_{5}$ & 0,23 & 0,13 \\
\hline $\mathrm{Na}_{2} \mathrm{O}$ & 0,23 & 0,06 \\
\hline $\mathrm{CaO}$ & 0,16 & 3,73 \\
\hline $\mathrm{MnO}$ & $<0,05$ & 0,27 \\
\hline $\mathrm{ZnO}$ & 0 & 0,44 \\
\hline $\mathrm{BaO}$ & 0 & 0,31 \\
\hline $\mathrm{Co}_{2} \mathrm{O}_{3}$ & 0 & $<0,1$ \\
\hline $\mathrm{Cr}_{2} \mathrm{O}_{3}$ & 0 & $<0,1$ \\
\hline $\mathrm{PbO}_{\mathrm{SrO}}$ & 0 & $<0,1$ \\
\hline $\mathrm{SrO}_{2}+\mathrm{HfO}$ & 0 & $<0,1$ \\
\hline $\mathrm{B}_{2} \mathrm{O}_{3}$ & 0 & $<0,1$ \\
\hline $\mathrm{Li}_{2} \mathrm{O}$ & 0 & 0 \\
\hline $\mathrm{Perda} \mathrm{ao} \mathrm{fogo}$ & 14,29 & 25,92 \\
\hline $\mathrm{Total}$ & 100 & 100 \\
\hline & &
\end{tabular}

\footnotetext{
* Contribuição técnica ao $69^{\circ}$ Congresso Anual da ABM - Internacional e ao 14ํㅡㄹ ENEMET - Encontro Nacional de Estudantes de Engenharia Metalúrgica, de Materiais e de Minas, 21 a 25 de julho de 2014, São Paulo, SP, Brasil.
} 


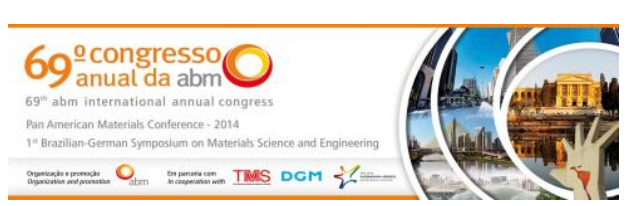

A Figura 4 apresenta o difratograma de raios $X$ da argila. $A$ análise do difratograma indica que os minerais predominantes são a caulinita, quartzo e ilita.

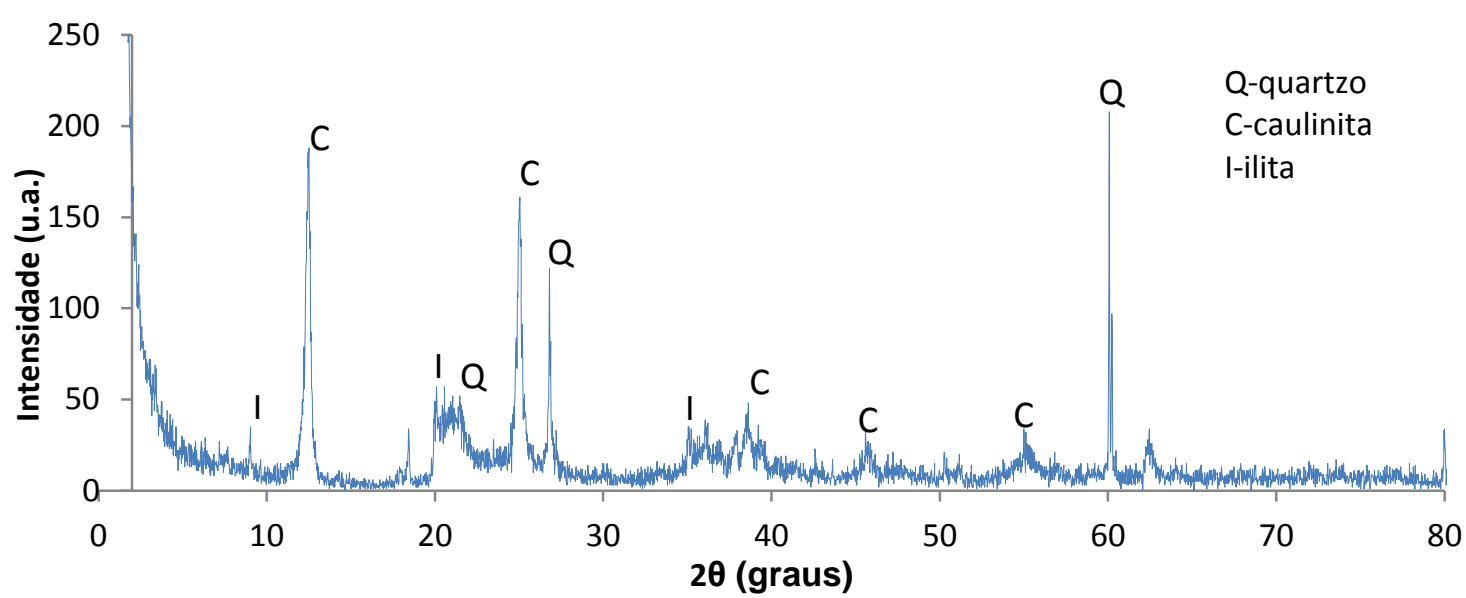

Figura 4. Difratograma de raios $X$ da argila

A Figura 5 apresenta o difratograma de raios $X$ da lama de alto forno. $A$ análise do difratograma de raios $X$ identifica as fases cristalinas associadas a compostos de ferro como a magnetita $\left(\mathrm{Fe}_{3} \mathrm{O}_{4}\right)$ e hematita $\left(\mathrm{Fe}_{2} \mathrm{O}_{3}\right)$, conforme indicou o elevado conteúdo de $\mathrm{Fe}_{2} \mathrm{O}_{3}$ detectado pela $\mathrm{FRX}$. Além do quartzo $\left(\mathrm{SiO}_{2}\right)$ e da calcita $\mathrm{CaCO}_{3}$. Os finos de coque presentes na LAF não podem ser identificados no DRX devido ao seu caráter amorfo [4].

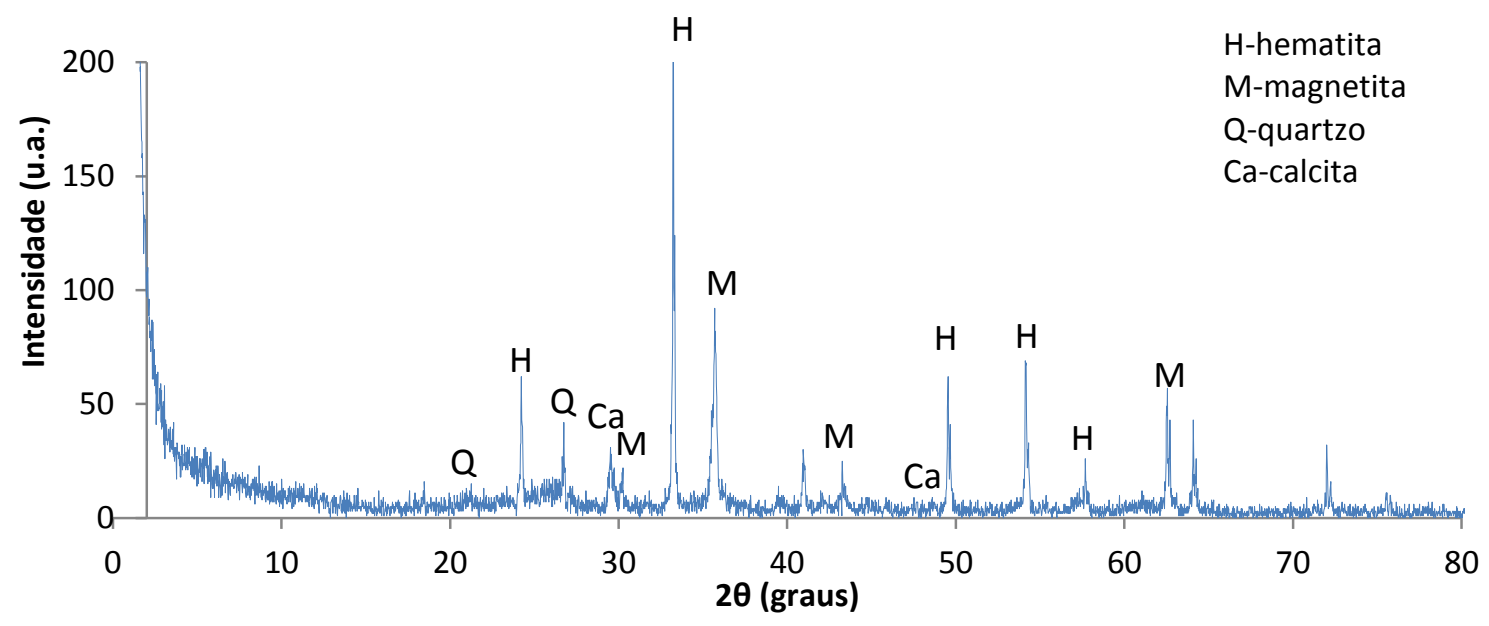

Figura 5. Difratograma de raios $X$ da lama de alto forno

O resultado da microscopia eletrônica indica que os grãos da argila (Figura 6 a, b) e da lama de alto forno (Figura $6 \mathrm{c}, \mathrm{d}$ ) apresentam formato irregular com tendência a forma de partículas lamelares, algumas dispersas e outras aglomeradas. A lama de alto forno contém grãos com textura mais rugosa que a argila. Os tamanhos dos grãos da argila variam de $60 \mu \mathrm{m}$ a $2 \mu \mathrm{m}$, enquanto os da lama variam de $62 \mu \mathrm{m}$ a $2 \mu \mathrm{m}$.

* Contribuição técnica ao 69 Congresso Anual da ABM - Internacional e ao 14ํㅡㄹ ENEMET - Encontro Nacional de Estudantes de Engenharia Metalúrgica, de Materiais e de Minas, 21 a 25 de julho de 2014, São Paulo, SP, Brasil. 


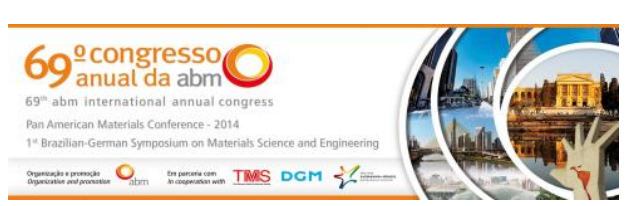

apresentou valores inferiores. Os menores valores de perda ao fogo, absorção de água e porosidade aparente ocorreram com a incorporação de $5 \%$ de lama de alto forno, e aumentaram gradativamente com o aumento do teor de resíduo.

Nas barras, a retração linear teve seu valor máximo nos corpos de prova com $40 \%$ de lama de alto forno, e a partir daí houve um aumento coerente da retração, o que deve ser devido à combustão dos finos de coque. A combustão desses finos também deve estar contribuindo para queima dos corpos de prova na temperatura testada.

Pode-se observar que em função do aumento do teor da lama de alto forno na massa argilosa houve aumento do percentual de matéria orgânica, o que já era esperado. E em função da liberação desta matéria orgânica durante a queima houve aumento no percentual da perda ao fogo o que gerou aumento na porosidade, na absorção de água e por consequência diminuição da resistência à compressão e à flexão nos corpos de prova. Portanto, a massa argilosa com incorporação de $5 \%$ de lama de alto forno apresenta maior potencial de uso em cerâmica vermelha, sem prejuízo das características avaliadas.

Considerando os valores prescritos por Santos [6] para avaliação de barras feitas com matérias-primas de massa cerâmica, absorção de água de $25 \%$ e massa específica aparente entre $1,5 \mathrm{~g} / \mathrm{cm}^{3}$ a $2,0 \mathrm{~g} / \mathrm{cm}^{3}$, ambos valores são atendidos com os corpos de prova com incorporação de $5 \%$ de lama de alto forno. Já a porosidade e a resistência à flexão obtidas nas barras não atendem aos limites prescritos pelo mesmo autor, máximo de 35\% e mínimo de $6 \mathrm{MPa}$, respectivamente em nenhum teor de lama de alto forno. Esse problema poderá ser contornado com alteração da temperatura de queima, já que os valores de porosidade e resistência à flexão, apesar de não terem atendido a prescrição, estão bem próximos dos valores indicados no teor de $5 \%$ de lama de alto forno.

Tabela 3. Resultados nas esferas

\begin{tabular}{ccccccc}
\hline $\begin{array}{c}\text { Teor } \\
\text { resíduo (\%) }\end{array}$ & $\begin{array}{c}\mathrm{PF} \\
(\%)\end{array}$ & $\begin{array}{c}\mathrm{AA} \\
(\%)\end{array}$ & $\begin{array}{c}\mathrm{PA} \\
(\%)\end{array}$ & $\begin{array}{c}\mathrm{MEA} \\
\left(\mathrm{g} / \mathrm{cm}^{3}\right)\end{array}$ & $\begin{array}{c}\mathrm{R} \mathrm{vQ} \\
(\%)\end{array}$ & $\begin{array}{c}\sigma_{\mathrm{CQ}} \\
(\mathrm{MPa})\end{array}$ \\
\hline 0 & 12,85 & 26,94 & 39,40 & 1,49 & 4,22 & 1,90 \\
\hline 5 & 13,27 & 27,39 & 38,79 & 1,44 & 4,65 & 2,77 \\
\hline 10 & 14,05 & 27,84 & 39,44 & 1,44 & 4,59 & 2,29 \\
\hline 20 & 15,42 & 28,14 & 40,09 & 1,42 & 4,73 & 2,67 \\
\hline 30 & 18,75 & 30,65 & 42,86 & 1,40 & 4,93 & 1,98 \\
\hline 40 & 18,91 & 30,00 & 42,06 & 1,40 & 5,83 & 1,66 \\
\hline 50 & 20,60 & 32,58 & 42,45 & 1,38 & 4,93 & 1,21 \\
\hline 60 & 22,31 & 33,60 & 46,04 & 1,37 & 5,34 & 0,73 \\
\hline 70 & 23,98 & 35,13 & 48,80 & 1,39 & 5,91 & 0,51 \\
\hline 80 & 25,53 & 37,25 & 50,34 & 1,35 & 6,42 & 0,21 \\
\hline 90 & 27,31 & 39,29 & 51,95 & 1,32 & 6,71 & 0,14 \\
\hline
\end{tabular}

Nota: $P F=$ perda de massa à queima ; $A A=$ absorção de água; $P A=$ porosidade aparente; $M E A=$ massa específica aparente; $R v Q=$ retração volumétrica após queima; $\sigma_{c q}=$ resistência à compressão após queima.

\footnotetext{
* Contribuição técnica ao 69 Congresso Anual da ABM - Internacional e ao 14ํㅡㄹ ENEMET - Encontro Nacional de Estudantes de Engenharia Metalúrgica, de Materiais e de Minas, 21 a 25 de julho de 2014, São Paulo, SP, Brasil.
} 


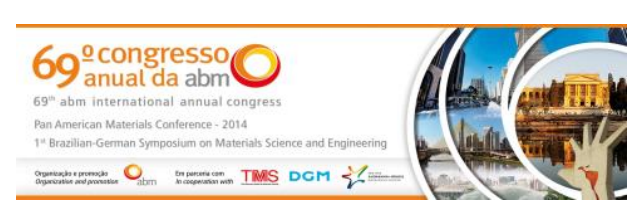

Tabela 4. Resultados nas barras

\begin{tabular}{ccccccc}
\hline $\begin{array}{c}\text { Teor resíduo } \\
(\%)\end{array}$ & $\begin{array}{c}\mathrm{PF} \\
(\%)\end{array}$ & $\begin{array}{c}\mathrm{AA} \\
(\%)\end{array}$ & $\begin{array}{c}\mathrm{PA} \\
(\%)\end{array}$ & $\begin{array}{c}\mathrm{MEA} \\
\left(\mathrm{g} / \mathrm{cm}^{3}\right)\end{array}$ & $\begin{array}{c}\mathrm{R} \\
(\%)\end{array}$ & $\begin{array}{c}\sigma_{\mathrm{FQ}} \\
(\mathrm{MPa})\end{array}$ \\
\hline 0 & 12,62 & 24,77 & 41,33 & 1,67 & 2,36 & 2,89 \\
\hline 5 & 13,38 & 24,46 & 37,09 & 1,52 & 2,07 & 5,23 \\
\hline 10 & 13,92 & 25,00 & 38,15 & 1,53 & 2,13 & 3,93 \\
\hline 20 & 15,53 & 25,86 & 38,93 & 1,51 & 2,18 & 2,72 \\
\hline 30 & 16,70 & 27,04 & 40,74 & 1,51 & 2,07 & 2,13 \\
\hline 40 & 17,99 & 27,89 & 41,67 & 1,49 & 2,14 & 1,79 \\
\hline 50 & 19,41 & 29,33 & 43,70 & 1,49 & 2,00 & 1,23 \\
\hline 60 & 20,74 & 30,73 & 46,34 & 1,49 & 1,97 & 0,98 \\
\hline 70 & 22,21 & 31,09 & 46,67 & 1,51 & 1,96 & 0,48 \\
\hline 80 & 23,60 & 33,10 & 48,78 & 1,50 & 2,09 & 0,32 \\
\hline 90 & 24,87 & 34,94 & 51,04 & 1,47 & 2,21 & 0 \\
\hline
\end{tabular}

Nota: $P F=$ perda de massa à queima ; $A A=$ absorção de água; $P A=$ porosidade aparente; $M E A=$ massa específica aparente; $R L Q=$ retração linear após queima; $\sigma_{F q}=$ resistência à flexão após queima.

\section{CONCLUSÃo}

A lama de alto forno é um resíduo constituído predominantemente por óxidos de ferro. Enquanto a argila estudada é sílico aluminosa com predomínio de minerais da caulinita.

A lama de alto forno contribuiu para melhoria da resistência mecânica nos corpos de prova, tanto nas esferas quanto nas barras, no teor de $5 \%$. E a partir desse teor de incorporação, ocasionou um aumento no percentual de absorção de água e de porosidade e diminuiu a resistência mecânica. Esse comportamento pode em parte ser atribuído à composição química da lama de alto forno, pois seus óxidos permanecem inertes durante a queima e o carbono orgânico aumenta a porosidade das peças. Entretanto, o carbono contido na lama de alto forno deve ter contribuído na queima completa dos corpos de prova na temperatura utilizada, que foi abaixo de $900^{\circ} \mathrm{C}$. O ferro contido na lama de alto forno também contribuiu para a cor avermelhada apresentada nos corpos de prova, típica das telhas e lajotas, produtos da cerâmica vermelha.

De acordo com os resultados obtidos recomenda-se que a lama de alto forno seja incorporada no teor máximo (em massa) de 5\% na massa argilosa.

\section{Agradecimentos}

Os autores agradecem a CAPES pelo apoio financeiro.

\section{REFERÊNCIAS}

1 Sumário Mineral. Sumário mineral 2012. V.32. Departamento Nacional de Produção Mineral. Coordenadores Thiers Muniz Lima, Carlos Augusto Ramos Neves. Brasília. 2012. 136p. [acesso em 02 mar. 2014]. Disponível em: https://sistemas.dnpm.gov.br/publicacao/mostra_imagem.asp?IDBancoArquivoArquivo $=7366$.

2 Instituto Aço Brasil, 2012. A indústria do aço no Brasil / Confederação Nacional da Indústria. Cadernos setoriais. Brasília. 50p. 2012. [acesso em 01 mai. 2013]. Disponível em:

\footnotetext{
* Contribuição técnica ao $69^{\circ}$ Congresso Anual da ABM - Internacional e ao 14ํㅡㄹ ENEMET - Encontro Nacional de Estudantes de Engenharia Metalúrgica, de Materiais e de Minas, 21 a 25 de julho de 2014, São Paulo, SP, Brasil.
} 
http://arquivos.portaldaindustria.com.br/app/conteudo_18/2013/09/23/4970/201310021 74604375684e.pdf.

3 Das B, Prakash S, Reddy PSR, MISRA VN. An overview of utilization of slag and sludge from steel industries. Resources, Conservation \& Recycling. 2007; 50(1): 40-57.

4 Vieira CMF, Dias CACM, Mothé AV, Sanchez R, Monteiro SN. Incorporation of blast furnace sludge into red ceramic. Cerâmica, 2007; 53: 381-387.

5 Almeida MLB, Melo GCB. Alternativas de usos e aplicações dos resíduos sólidos das indústrias independentes de produção de ferro-gusa do estado de Minas Gerais. In: 21ํㅡㄴ Congresso Brasileiro de Engenharia Sanitária e Ambiental. set/2001. p.1-13. João Pessoa. Paraíba.

6 Santos PS. Tecnologia das argilas. V1-2. São Paulo: Edgard Blucher; 1975.

7 Mothé AV. Utilização da lama de alto-forno em cerâmica vermelha. [Mestrado em Engenharia e Ciência dos Materiais]. Rio de Janeiro: Universidade Estadual do Norte Fluminense; 2008.

8 Carreiro RS. Geração de novos produtos cerâmicos com a incorporação de lama de alto forno. Anicer. 2011; 14(72): 26-32. [acesso em 23 jun. 2013]. Disponível em: http://www.anicer.com.br/arquivos/revista/revista_72.pdf.

9 Ferreira FHJ, Grillo FF, Nascimento R C, Tenório J A S. Análise das propriedades de pelotas fabricadas com adição de lama de alto forno. In: 66 ABM International Congress, 2011, São Paulo. ISBN: 978-1-61839-113-1. ISSN: 1516-392X.

10 Oliveira FR, Silveira CS, Assis PS. Caracterização química e estudo de possíveis aplicações para a lama gerada em alto forno. In: 5ํㅡㄹ Encontro Nacional de Tecnologia Química. 2012. Maceió/Alagoas-Brasil. [acesso em 26 jun. 2013]. Disponível em: http://www.abq.org.br/entequi/2012/trabalhos/50/50-81-13307.html.

11 Associação Brasileira de Normas Técnicas. NBR 6459: Solo - determinação de limite de liquidez. Rio de Janeiro, 1984.

12 Associação Brasileira de Normas Técnicas. NBR 7180: Solo - Determinação do limite de plasticidade. Rio de Janeiro, 1984.

13 Associação Brasileira de Normas Técnicas. NBR 6457: Amostras de solo - preparação para ensaios de compactação e ensaios de caracterização. Rio de Janeiro, 1986.

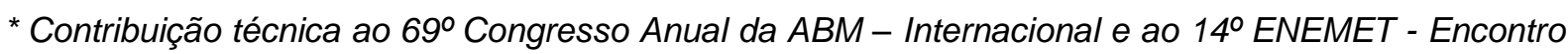
Nacional de Estudantes de Engenharia Metalúrgica, de Materiais e de Minas, 21 a 25 de julho de 2014, São Paulo, SP, Brasil.
} 